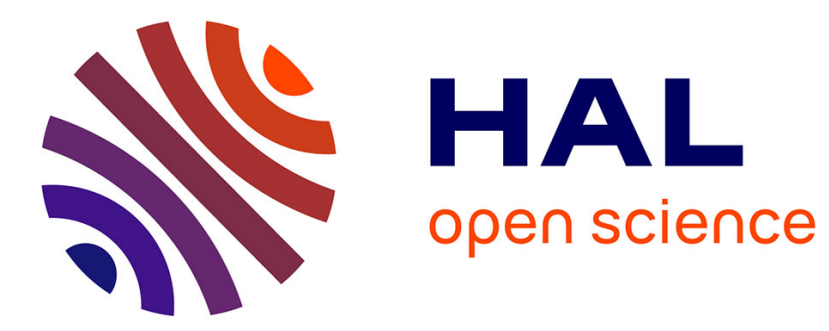

\title{
Fracture processes imaging in concrete using nonlinear ultrasound
}

\author{
Martin Lott, Marcel C Remillieux, Vincent Garnier, T.J. J Ulrich, Pierre-Yves
}

Le Bas, Arnaud Deraemaeker, Cédric Dumoulin, Cédric Payan

\section{- To cite this version:}

Martin Lott, Marcel C Remillieux, Vincent Garnier, T.J. J Ulrich, Pierre-Yves Le Bas, et al.. Fracture processes imaging in concrete using nonlinear ultrasound. NDT \& E International, 2021, pp.102432. 10.1016/j.ndteint.2021.102432 . hal-03154960

\section{HAL Id: hal-03154960 \\ https://hal.science/hal-03154960}

Submitted on 1 Mar 2021

HAL is a multi-disciplinary open access archive for the deposit and dissemination of scientific research documents, whether they are published or not. The documents may come from teaching and research institutions in France or abroad, or from public or private research centers.
L'archive ouverte pluridisciplinaire HAL, est destinée au dépôt et à la diffusion de documents scientifiques de niveau recherche, publiés ou non, émanant des établissements d'enseignement et de recherche français ou étrangers, des laboratoires publics ou privés. 


\section{Fracture processes imaging in concrete using nonlinear ultrasound}

2 Martin Lott ${ }^{1,2}$, Marcel C. Remillieux ${ }^{3}$, Vincent Garnier ${ }^{2}$, T. J. Ulrich ${ }^{4}$, Pierre-Yves Le Bas ${ }^{4}$, Arnaud

3 Deraemaeker ${ }^{5}$, Cédric Dumoulin ${ }^{5}$, Cédric Payan ${ }^{2}$

$4 \quad{ }^{1}$ Université Grenoble Alpes, Université Savoie Mont Blanc, CNRS, IRD, IFSTTAR, ISTerre, 38000

5 Grenoble, France

$6 \quad{ }^{2}$ Aix Marseille Univ, CNRS, Centrale Marseille, LMA, Marseille, France

$7 \quad{ }^{3}$ Geophysics Group (EES-17), Los Alamos National Laboratory, Los Alamos, NM, 87545, USA

$8{ }^{4}$ Detonation Science and Technology Group (Q-6), Los Alamos National Laboratory, Los Alamos,

9 NM, 87545, USA

${ }^{5}$ Université Libre de Bruxelles, BATir Department, F. D. Roosevelt Av 50, 1050 Brussels, Belgium

\section{Abstract}

This paper shows the complementarity of two nonlinear ultrasonic imaging methods to characterize closed macro cracks in concrete. A time reversal mirror is used to locally probe and image the nonlinearity of a cracked region. Two nonlinear parameters are extracted to map the cracked region. The image obtained using the first parameter relates the harmonic generation due to the contact and frictional behaviors at the crack lips, correlated with vibro-thermography imaging of the same crack. The image obtained using the second parameter is based on the conditioning of the material induced by distributed micro cracks arising from the fracture process zone. These results show a great potential for characterization of fracture processes in concrete, with the possibility to uncouple the effects of the crack itself from surrounding distributed micro damage.

Keywords: Nonlinear ultrasound, Concrete, Cracks, Fracture process zone

\section{Highlight:}

- Nonlinear ultrasound can image and distinguish fracture processes in concrete

- Nonlinear responses from the fracture process zone and the crack lips are separated

- The results are correlated with vibro-thermography images 


\section{Introduction}

In civil engineering, increasingly more stringent safety and maintenance requirements have called for more sophisticated detection and imaging NDT tools. This is particularly true in the nuclear-energy industry, in the context of license renewal and need for structural assessment. Ultrasonic assessment of concrete structures has been successfully achieved since 1990's with the possibility to image complex structures using tomographic approaches [1,2]. Ultrasonic crack-depth estimation in concrete is standardized [3], based on low-frequency (tens of $\mathrm{kHz}$ ) wave propagation. However, the resolution is limited by the wavelength and only the opened portion of the crack can be detected. More refined methods based on the multiple scattering of higher-frequency waves [4] are more sensitive to the complex morphology of the crack, including partially opened cracks [5]. Nonlinear-ultrasonic-based methods have been proven efficient in detecting many types of damage and pathologies in concrete $[6,7,8,9]$. Nonlinear ultrasound has also been successfully employed to probe closed cracks $[10,11]$ and exhibited a promising sensitivity. Even if the industrial civil engineering community reveals a growing interest for these methods, nonlinear ultrasonic inspection of concrete has been limited to laboratory studies.

So far, ultrasonic imaging of closed cracks remains a challenge. As for characterization, ultrasonic imaging can be achieved [12] but with a sensitivity limited to the large wavelength employed and to the opened portion of the crack. Again, higher frequencies fall in the multiple scattering regime into which standard methods do not apply. Recent research based on higher frequency diffuse waves showed the ability to image macro crack in laboratory samples [13] as well as real structures [14]. However, this approach only applies to image variations, i.e., crack propagation or crack opening due to external loadings, and only image the opened portions of the cracks.

The aim of this paper is to investigate the potential of methods based on nonlinear acoustics for closedcrack imaging. The imaging method employed here is based on time reversal, which focuses elastic energy at a prescribed location [15]. A study of the amplitude dependence of the elastic response allows then to locally probe the nonlinearity of the medium. Repeating this experiment over a regular grid spanning a region of interest on the surface of the concrete may provide a map of the nonlinearity. Such a method was already applied to probe distributed damage in concrete [16], as well as in other materials 
such as metals [17]. This paper shows that contact phenomena at the crack lips are well imaged using a method based on harmonic generation. These physical phenomena are also validated using active vibrothermography. The fracture process zone surrounding the main crack lips exhibits micro damage occurring during fracture formation [18]. This zone is also imaged using a time-delay method, similar to the one used in [16].

\section{Materials and Methods}

We study a notched rectangular prism of ordinary concrete with dimensions of $10 \times 10 \times 60 \mathrm{~cm}^{3}$. The composition of the sample is provided in table. 1 .

Table.1. Concrete sample composition

\begin{tabular}{|l|l|}
\hline CEM I 52.5 N PMES CP2 (Saint Vigor, FR) & $340 \mathrm{~kg} / \mathrm{m}^{3}$ \\
\hline Sand 0/4 (Bernières, FR) & $739 \mathrm{~kg} / \mathrm{m}^{3}$ \\
\hline Gravel 8/22 (Bernières, FR) & $1072 \mathrm{~kg} / \mathrm{m}^{3}$ \\
\hline Total water & $184 \mathrm{~kg} / \mathrm{m}^{3}$ \\
\hline
\end{tabular}

A macro-crack departing from the notch was generated in the sample via a three-point bending test. Photographs of the sample and crack are shown in Figure 1(a,c) as well as the force versus vertical displacement curve recorded during the mechanical test (Fig.1b).

In the following, our ultrasonic measurements capitalize on a well-known property of elastic waves to focus a high level of elastic energy in time and space, namely a Time Reversal Mirror (TRM). A description of time reversal and its application to non-destructive testing was given by Anderson et al. [19]. The reciprocal TRM version employed in this study provides an opportunity to focus energy remotely from a set of source transducers. After the forward step has been conducted independently with each of these source transducers, they can be synchronized to emit simultaneously their TR signals and focus elastic wave energy at a point of interest, thus allowing relatively large strain amplitudes to be reached. The large strain amplitude is necessary for the study of nonlinearity while the localized excitation is necessary for imaging application, to probe the nonlinearity of the material locally (e.g., near a crack). 
The sample was instrumented with 10 piezoelectric disks, which were used as source transducers randomly glued on the six faces of the sample. The piezoelectric disks were made by APC International using material type 855 (Navy VI), had a diameter of $25.4 \mathrm{~mm}$ and thickness of $6.3 \mathrm{~mm}$. Devcon® 5 Minute epoxy was used to bond the transducers to the concrete sample. The source transducers were individually driven with signals generated by 16-bit waveform-generator cards (National Instrument, PXI-5421) and amplified 50 times by power amplifiers (Tabor Electronics, Model 9400). The out-ofplane component of the particle velocity was measured on the surface of the sample using a laser Doppler vibrometer (Polytec OFV-303). The laser head was mounted on a moving stage capable of scanning the vibration field on a region of interest. The data measured by this instrument was digitized at a sampling rate of $10 \mathrm{MHz}$ (National Instrument, PXI-4122) with a sensitivity of $5 \mathrm{~mm} / \mathrm{s} / \mathrm{V}$. The linearity of the setup was checked on a plexiglass sample.

In this experiment, the band-limited impulse response between the sources and the receiver (focal point) are obtained using a combination of chirp signals and cross-correlations, to increase the signal-to-noise ratio in the frequency band of interest. The chirp signal used in the forward step had a frequency range of $50 \mathrm{kHz}$ to $150 \mathrm{kHz}$, which encompasses the operating frequency of the piezoelectric source at 80 kHz. The full TRM procedure used in this study is gathered in Figure 2. Figure 2a shows the ten forward signals (band-limited impulse responses) obtained independently for the ten source transducers by crosscorrelation with the laser signal at the focal point. Once reversed in time, the summation of the ten sources give rises to a localized signal in time (Fig 2b) and space (Fig 2c). In Figure 2c, the white cross denotes the point in space where the ten signals in Figure 2a and the time reversed summation is recorded. Theoretically, the full-width half-maximum (FWHM) size of a focal spot is equal to a half wavelength at the center frequency of the pulse [20]. As shown in Figure 2c, the size of the measured focal spot is approximately $1 \mathrm{~cm}$. Considering a center frequency of $100 \mathrm{kHz}$, we estimate the wave speed to be approximately $2000 \mathrm{~m} / \mathrm{s}$, which would correspond to the wave speed of surface waves in concrete [21]. In other words, the focal signal in this particular setup is mainly produced by surface waves. The local (at the focal spot) strain amplitude is approximated as the ratio between the out-ofplane particle velocity and the mean wave speed as in [16]. This estimation of the strain amplitude is essential for quantitative nonlinear studies [16,22]. 
TR-based imaging was performed around the crack and above the notch, within a square region of $60 \times$ $60 \mathrm{~mm}^{2}$. The scan grid consisted of 1600 points with a spatial resolution of $1.5 \mathrm{~mm}$. At each scan point, the TR experiment was repeated at 10 amplitudes (before amplification): 5 negative amplitudes $x_{i}^{-}=-$ $1 \mathrm{~V},-0.8 \mathrm{~V},-0.6 \mathrm{~V},-0.4 \mathrm{~V},-0.2 \mathrm{~V}$, and 5 positive amplitudes $x_{i}^{+}=0.2 \mathrm{~V}, 0.4 \mathrm{~V}, 0.6 \mathrm{~V}, 0.8 \mathrm{~V}, 1 \mathrm{~V}$. The phase shift in the amplitude sweep will be useful in the nonlinear analysis. The TR signals obtained at a point of focus on the scanning grid with the 10 source amplitudes are shown in Figure 2a. Two nonlinear parameters are extracted from this set of data: one that is representative of a diffuse damage of the sample [16] and one that is representative of clapping phenomena at the crack lips interface [7,17].

The first parameter is related to the time at which the maximum signal amplitude is achieved at the focal point, which we will refer to as focal time. The signals shown in Figure 3a-1 are used for this analysis. The dependence of the focal time on the vibration amplitude is related to nonclassical nonlinearity and will be described by a parameter $\alpha$ [16]. The focal time at the lowest vibration amplitude of the experiment is used as a linear reference against which the focal times at the larger vibration amplitudes are compared to compute a time delay using cross correlation. The time delay experienced by the focal signal as a function of strain amplitude at this particular focal point is shown in Fig. 3a-2 for the 5 positive source amplitudes (from $0.2 \mathrm{~V}$ to $1 \mathrm{~V}$ ). The slope of the linear fit for this set of time delays is the parameter $\alpha$ used in this analysis.

The second parameter is estimated using the pulse inversion harmonic processing [23]. In brief, when two waves of equal amplitude but opposite phase propagate in a nonlinear material at a frequency $f_{0}$, the linear component of the summed waves (spectral content at the fundamental frequency $f_{0}$ ) should vanish while some of the nonlinear components (spectral content around the even harmonic frequencies, e.g., $2 f_{0}$ ) should be doubled. This technique has been amply used to enhance the signal to noise ratio of harmonic imaging in the medical field. The harmonic generation appears in the frequency band 150$250 \mathrm{kHz}$, above the sources bandwidth $(150 \mathrm{kHz})$ and below the signal to noise ratio $(250 \mathrm{kHz})$, depicted with a blue background area in Figure $3 b-1$. The summed focused signal $\left(x_{i}^{+}+x_{i}^{-}\right)$are then filtered in this frequency band $(150-250 \mathrm{kHz})$. The residual intensity is reported to the strain amplitude in Figure 
3b-2. We observe a quadratic evolution of this parameter with the strain amplitude. The retained value for this nonlinear parameter is the quadratic term $\beta$ of the fitted polynomial. The asymmetry of the focused signals is representative of a difference between pushing and pulling at the surface. It is expected to be sensitive to the crack interface through clapping phenomena [17].

The procedures are repeated for all 1600 points of the scanning grid to provide a map of the nonlinear parameters. The linear and quadratic regression are calculated only for the 5 available strain amplitudes. However, each point results from the combination of two independently ran signals. In addition, the spatial measurement density $\left(1.5 \mathrm{~mm}^{2}\right)$ in view of the mean wavelength $(1 \mathrm{~cm})$ allows the spatial smoothing of the obtained images.

\section{Results and discussion}

The two images obtained using nonlinear ultrasound are displayed on Figure $4 \mathrm{a}$ and $4 \mathrm{~b}$ respectively for $\alpha$ and $\beta$ parameters.

Fig. 4a reveals several zones surrounding the crack with a higher $\alpha$ parameter. In was shown in previous work [16] that this parameter was related to the amount of micro-cracking damage in concrete. The size of the micro-cracked region occurring before coalescence of connected microcracks is known to depend on the size of the aggregates [18]. Our concrete sample being made with $22 \mathrm{~mm}$ aggregates, the size of the fracture process zone is expected to scale about $2 \mathrm{~cm}$ apart from the crack [18,24]. This corresponds to the extent of the highest $\alpha$ values shown in Fig $4 \mathrm{~b}$. This map of $\alpha$ seems to be a reasonable representation of the fracture process zone $[18,25,26]$.

In Figure $4 \mathrm{~b}$, the parameter $\beta$ exhibits a relatively large dynamic range and is thus displayed in log scale for clarity. The highest $\beta$ values are observed along the crack lips and do not overlap with the map of the $\alpha$ parameter. We explain the results as follow: some parts of the cracks can be opened and closed by the push-pull induced by the ultrasonic focusing, generating the strong asymmetries in the signals, thus producing a strong residual energy. As a correlation step, a vibro-thermography experiment is carried out using the same sources at the same frequencies. One of the piezoelectric devices is driven at $400 \mathrm{Vpp}$ (maximal amplitude reachable by the amplifiers), at the frequency which produces the highest amplitude in the sample $(80 \mathrm{kHz})$. The images are recorded using a FLIR SC8200 IR camera. The image is obtained 
using the protocol described by Remillieux et al. [27] to image cracks in metal. The image (Fig.4c) reveals high intensity spots occurring during wave propagation in the crack region. The apparent correlation of both images in Figures $(4 \mathrm{~b}, 4 \mathrm{c})$ suggests that both techniques are sensitive to the same physical features of the crack despite the wavelength of the source signal being much larger than those features.

\section{Conclusion}

This paper demonstrates the ability of nonlinear ultrasonic methods to image macrocrack processes in concrete. The time reversal method employed here allows to image independently the fracture process zone and the crack lips using two physical parameters $(\alpha$ and $\beta)$ respectively sensitive to the presence of diffused micro-damage and friction/clapping phenomena. The beta mapping is correlated with a vibrothermography image. The alpha mapping reveals a micro-damaged zone corresponding to the size of already observed FPZ in samples with aggregate size of about $20 \mathrm{~mm}$.

In view of field applications, the method employed here presents the advantage that the location of the sources is not an issue and it does not affect the resolution which is driven by the scan span defined with the laser. However, the main limitation is the surface nature of the measurements even if the information is also related to the penetration depth of the focal still driven by the wavelength. Another limitation of the present experiment is the time needed to perform such a scan (about $80 \mathrm{~h}$ ) even if the spatial resolution could be reduced to meet more realistic industrial conditions. Nonetheless, the main conclusion concerns the ability of the two nonlinear ultrasonic parameters to image and characterize fracture processes in concrete. From a more practical standpoint, recent technological advances using ultrasonic phased arrays in concrete [28] could allow to image a macrocracks in the bulk of concrete using nonlinear phenomenon similarly as nonlinear imaging methods employed in metals [29] in the near future, once high amplitude waves will be available on such equipment.

\section{Acknowledgments}

The authors thank the French National research Agency for funding [ANR ENDE 11 RSNR 0009]. 


\section{References}

192

193

[1] O. Büyüköztürk, Imaging of concrete structures, NDT \& E Int. 31 (4) (1998) 233-243

194

[2] P. Rivard, G. Ballivy, C. Gravel, F. Saint-Pierre, Monitoring of an hydraulic structure affected by

ASR: A case study, Cem. Concr. Res. 40 (4) (2010) 676-680

196

[3] BS 1881: Part 203, Recommendations for measurement of the velocity of ultrasonic pulses in

197

198

199

200

201

202

203

204

205

206

207

208

209

210

211

212

213

214

215 concrete, London, 1986.

[4] A. Quiviger, C. Payan, J.F. Chaix, V. Ganier and J. Salin, Effect of the presence and size of a real macro-crack on diffuse ultrasound in concrete, NDT \& E Int. 45 (2012) 128-132.

[5] A. Quiviger, A. Girard, C. Payan, J.F. Chaix, V. Garnier, J. Salin, Influence of the depth and morphology of real cracks on diffuse ultrasound in concrete: a simulation study, NDT \& E Int. 60 (2013) 11-16.

[6] P. Antonaci, C.L.E. Bruno, A.S. Gliozzi, M. Scalerandi, Monitoring evolution of compressive damage in concrete with linear and nonlinear ultrasonic methods, Cem. Concr. Res. 40 (7) (2010) 11061113.

[7] J. Chen, A.R. Jayapalan, J.Y. Kim, K.E. Kurtis, L.J. Jacobs, Rapid evaluation of alkali-silica reactivity of aggregates using a nonlinear resonance spectroscopy technique, Cem. Concr. Res. 40 (2010) 914-923.

[8] F. Bouchaala, C. Payan, V. Garnier and J.P. Balayssac, Carbonation Assessment in Concrete by Nonlinear Ultrasound, Cem. Concr. Res. 41 (2011) 557-559.

[9] C. Payan, V. Garnier, J. Moysan, Effect of water saturation and porosity on the nonlinear elastic response of concrete, Cem. Concr. Res. 40 (3) (2010) 473-476

[10] P. Antonaci, C.L.E. Bruno, P.G. Bocca, M. Scalerandi, A.S. Gliozzi, Nonlinear ultrasonic evaluation of load effects on discontinuities in concrete, Cem. Concr. Res. 40 (2010) 340-346.

[11] J.-P. Zardan, C. Payan, V. Garnier and J. Salin, Effect of the presence and size of a localized nonlinear source in concrete, J. Acoust. Soc. Am. 128(2010) EL38-EL42.

[12] H. Choi, G. Palacios, J.S. Popovics, and S.H. Chao, Monitoring Damage in Concrete Columns Using Ultrasonic Tomography, ACI Struct. J. (2018) 545-558. 
and characterizing a crack in concrete with diffuse ultrasound: A four-point bending test, J. Acoust. Soc. Am. 138 (2015) 232-241.

222

[14] Y Zhang, E Larose, L Moreau, G d'Ozouville, Three-dimensional in-situ imaging of cracks in concrete using diffuse ultrasound, Struct. Health Monit. 17 (2019) 279-284.

[15] Anderson, B.E., Remillieux, M.C., Le Bas, P.-Y. and Ulrich, T.J., 2019. Time reversal techniques.

In B. Kundu (Ed), Nonlinear Ultrasonic and Vibro-Acoustical Techniques for Nondestructive Evaluation, 2019, pp. 547-581.

[16] C. Payan, T.J. Ulrich, P.Y. Le Bas, M. Griffa, P. Schuetz, M.C. Remillieux, T.A. Saleh, Probing material nonlinearity at various depths by time reversal mirror, App. Phys. Lett. 104 (2014) 144102.

[17] T. J. Ulrich, P. A. Johnson, R.A. Guyer, Interaction Dynamics of Elastic Waves with a Complex Nonlinear Scatterer through the Use of a Time Reversal Mirror, Phys. Rev. Lett. 98 (2007) 104301.

[18] K. Otsuka, H. Date, Fracture process zone in concrete tension specimen, Eng. Fract. Mech. 65 (2000) 111-131.

[19] B.E. Anderson, M. Griffa, C. Larmat, T.J. Ulrich, P.A. Johnson, Time reversal. Acoust. Today 4(1) (2008) 5-16

[20] M.C. Remillieux, B.E. Anderson, T.J. Ulrich, P.Y. Le Bas, C. Payan, Depth profile of a timereversal focus in an elastic solid, Ultrasonics 58 (2015) 60-66.

[21] Q.A. Vu, V Garnier, J.F. Chaix, C. Payan, M. Lott, J.N. Eiras, Concrete cover characterisation using dynamic acousto-elastic testing and Rayleigh waves, Constr. Build. Mater. 114 (2016) 87-97.

[22] M. Lott, M.C. Remillieux, V Garnier, PY Le Bas, TJ Ulrich, C Payan, Nonlinear elasticity in rocks:

A comprehensive three-dimensional description, Phys. Rev. Mat. 1 (2) (2017), 023603.

[23] P.N. Burns, D. Hope Simpson, M.A. Averkiou, Nonlinear imaging, Ultrasound in Medicine and Biology (26) (2000), S19 - S22

[24] S. Muralidhara, B.R. Prasad, H. Eskandari, B.L. Karihaloo, Fracture process zone size and true 244 fracture energy of concrete using acoustic emission, Constr. Build. Mater. 24(4) (2010), 479-486.

245 [25] D. Zhang, K. Wu, Fracture process zone of notched three-point-bending concrete beams, Cem. 
247 [26] H. Mihashi, N. Nomura, S. Niiseki, Influence of aggregate size on fracture process zone of concrete 248 detected with three dimensional acoustic emission technique, Cem. Concr. Res. 21 (5) (1991) 737-744. 249 [27] M.C. Remillieux et al., Detecting and imaging stress corrosion cracking in stainless steel, with 250 application to inspecting storage canisters for spent nuclear fuel, NDT \& E Int. 109 (2020) 102180.

251 [28] E. Niederleithinger, S. Maak, F. Mielentz, U.A. Effner, C. Strangfeld, J. Timofeev, Review of recent developments in ultrasonic echo testing of concrete, 5th International Conference on Smart

253 Monitoring, Assessment and Rehabilitation of Civil Structures, August 2019 Potsdam, Germany (2019)

254 [29] Y. Ohara, H. Nakajima, S. Haupert, T. Tsuji, T. Mihara, Nonlinear ultrasonic phased array with 255 fixed-voltage fundamental wave amplitude difference for high-selectivity imaging of closed cracks, J. Acoust. Soc. Am. 146 (2019) 266-277. 

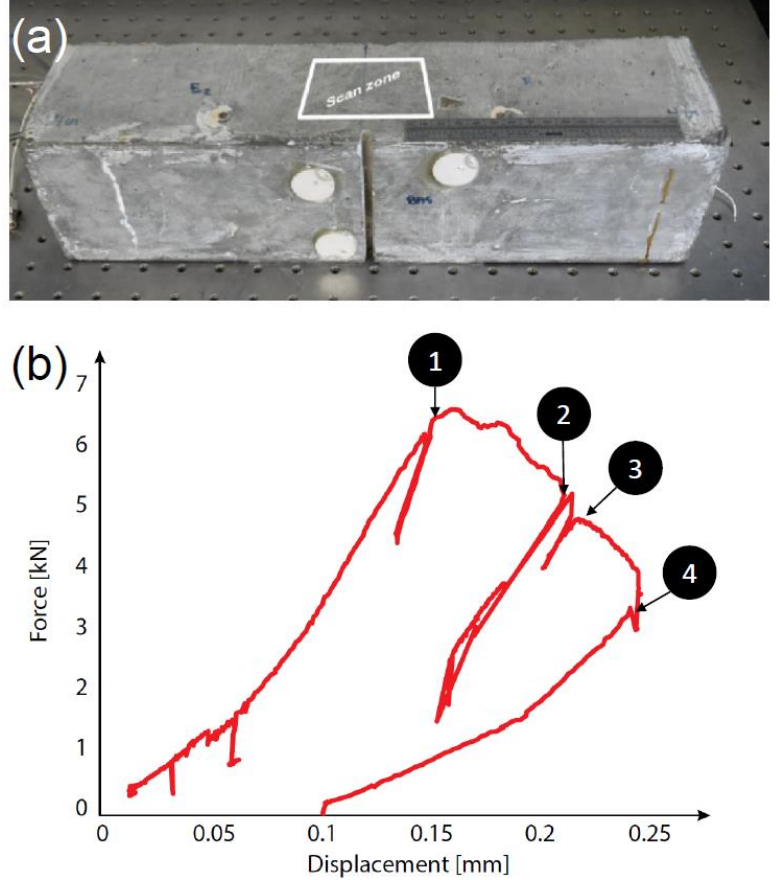
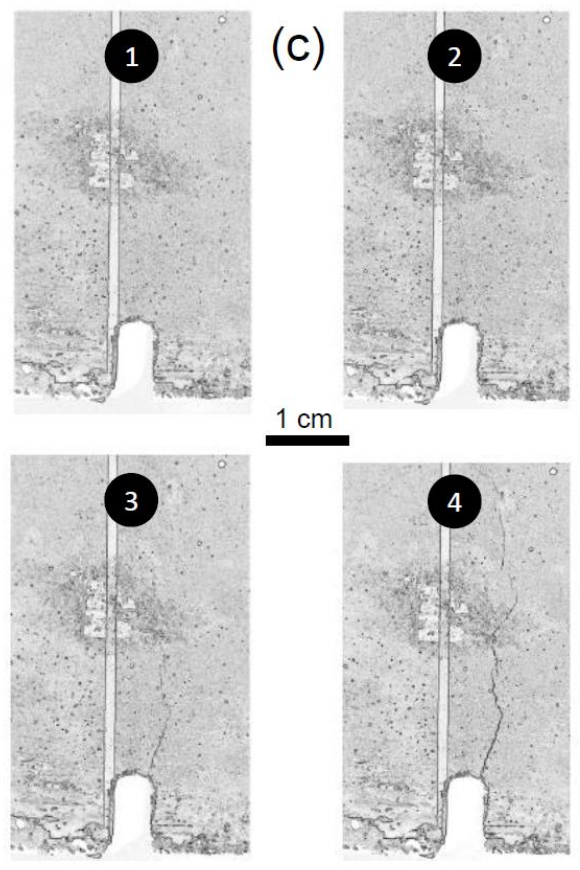

258 
(a)

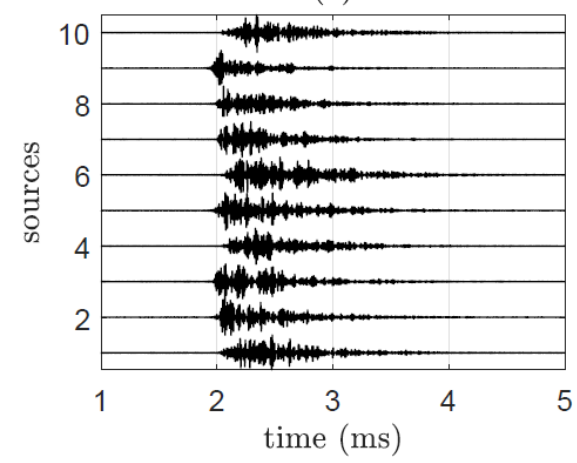

(c)

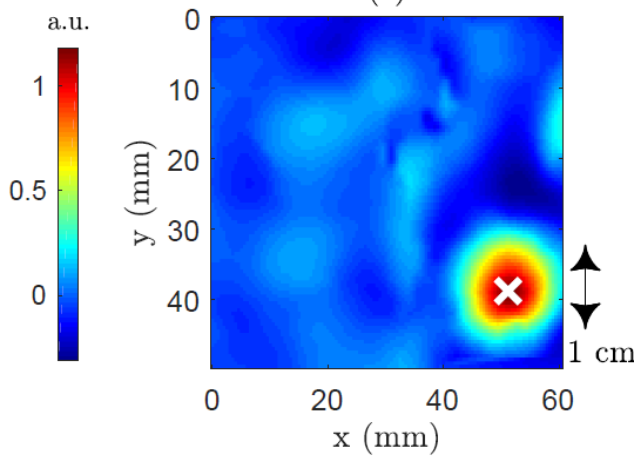

(b)

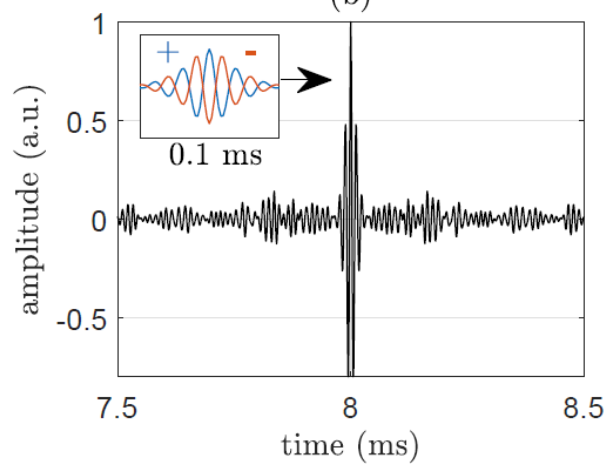

(d)

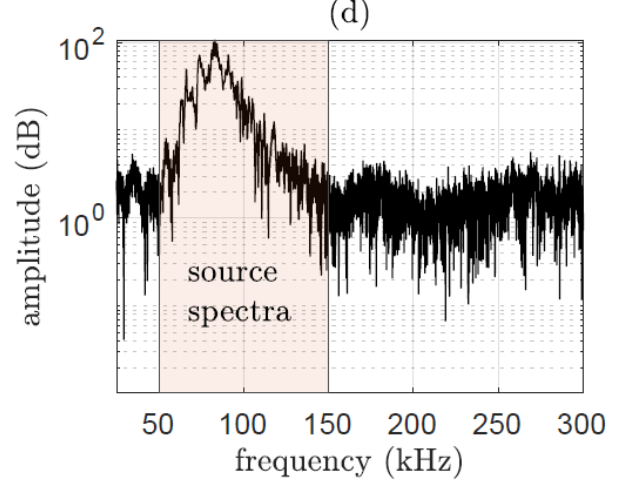

271 Figure 2: Time reversal mirror principle. (a) Ten forward signals sent by the sources. (b) Focused signal

272 in time produced by rebroadcasting the time reversed version of the forward signals. (c) Focal spot in

273 space (white-cross is the point where TRM is applied) recorded at focal time. (d) Frequency content of 274 the focus signal. The input source spectra is highlighted by a red background area. 

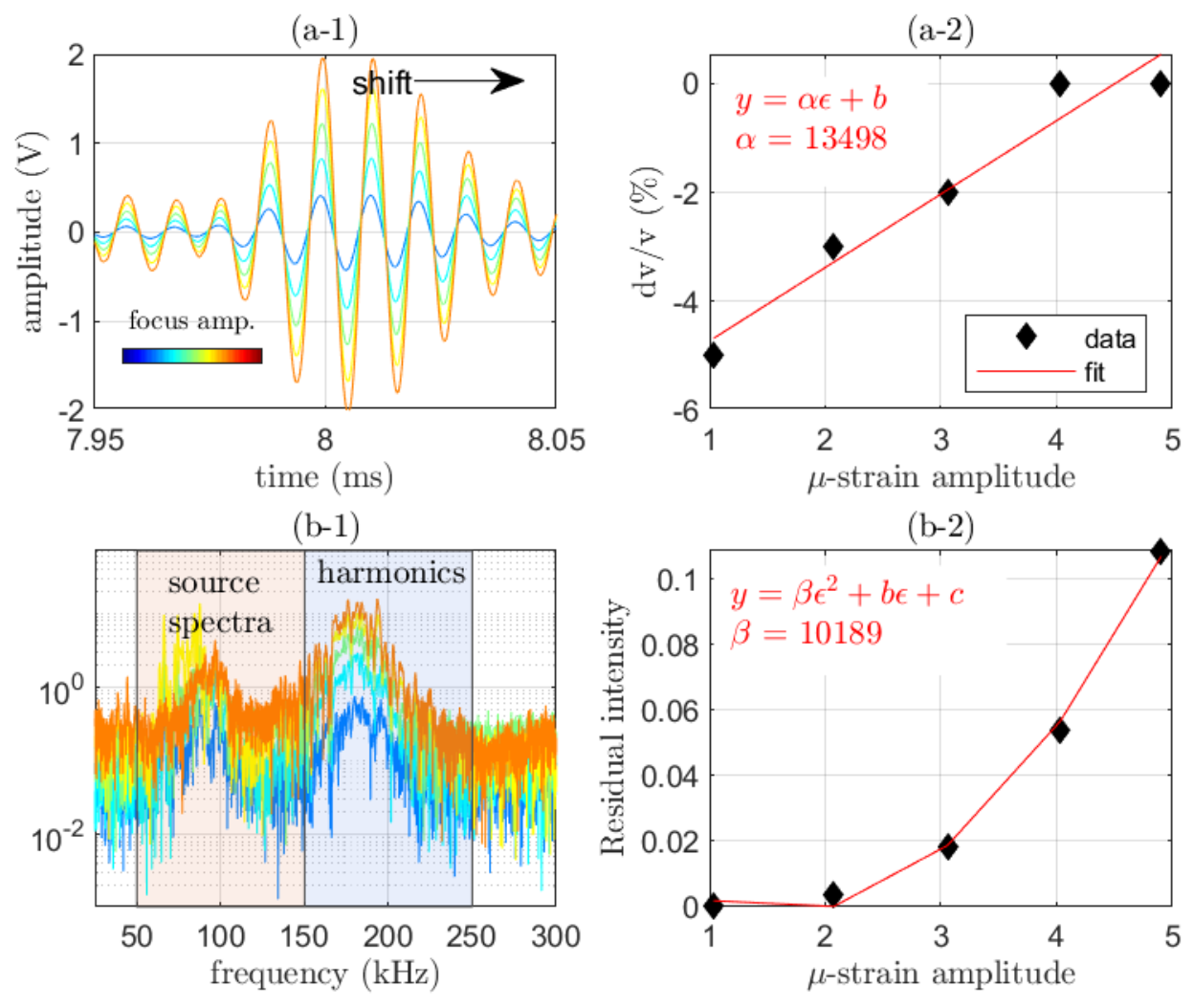

277 Figure 3: Representative results for the extraction of nonlinear parameters. (a) $\alpha$ and (b) $\beta$ are extracted

278 from the measured focused signal. (a-1) Five positive focused signals. (a-2) Time shift (or $\Delta \mathrm{t} / t_{0}$ ) at the

279 focal spot as a function of amplitude (black diamond) with a linear regression (red curve and equation).

280 The color code (blue to red) represents the 5 focused amplitudes. (b-1) Residual spectra for the summation of the five positive and negative signals. The red background area is the linear frequency band (that of the source signal) and the blue background area is the frequency width considered for the harmonic generation measurement. (b-2) Residual intensity into the harmonic frequency band a function of strain amplitude (black diamond) and quadratic regression (red curve and equation). 
(a)

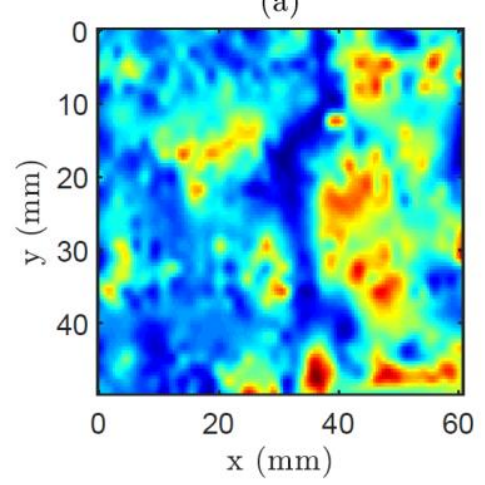

290

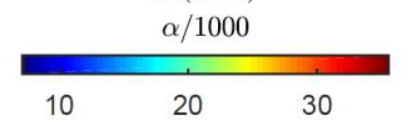

(b)

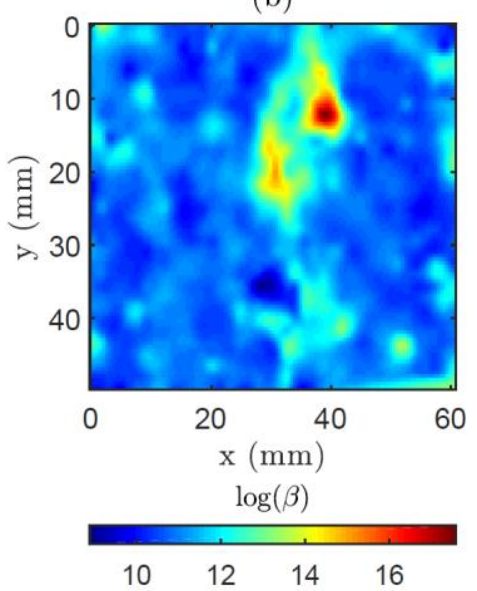

(c)

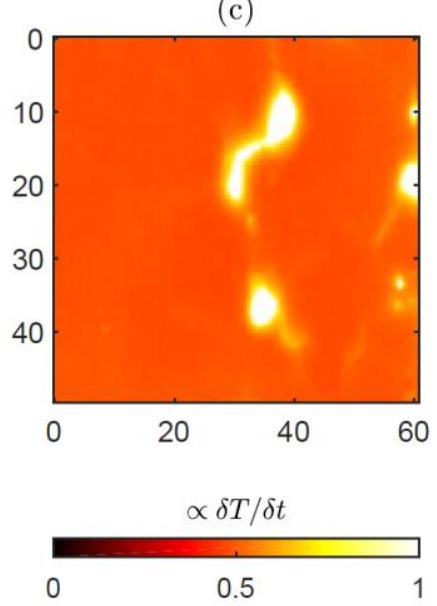

291 Figure 4: Experimental images of the cracked region. (a) Nonlinear $\alpha$ parameter. (b) Harmonic 292 generation ( $\beta$ parameter). (c) Vibro-thermography image: first derivative of the temperature with respect 293 to time (the reader can refer to [23] for more details). 